\title{
PCATool: instrumento de avaliação da atenção primária
}

\author{
PCATool: primary care assessment tool \\ PCATool: instrumento de evaluación de la atención primaria
}

Armando Henrique Norman. MSc em Antropologia Médica pela Durham University. editor.rbmfc@sbmfc.org.br (Autor correspondente)

Josane Araujo Norman. Editora Adjunta RBMFC. editoradj1.rbmfc@sbmfc.org.br

A Revista Brasileira de Medicina de Família e Comunidade (RBMFC) encerra o ano de 2013 com uma edição em comemoração ao nascimento da Dra. Barbara Starfield em 18 de dezembro (18/12/1932 - 10/6/2011). A foto da capa, intitulada "Desayuno en Buitrago de Lozoya" retrata a amizade entre Barbara Starfield, seu marido Neil "Tony" Holtzman e Juan Gérvas e Mercedes Pérez Fernández (autora da foto), na qual desfrutam e compartilham a vida à mesa. A mesa também faz referência a uma característica marcante de Starfield: a de nutriz (do latim nuctrix, que possui a capacidade de nutrir; que sustenta). Como afirmou seu marido Tony: - "Ela fez isso por meio de sua pesquisa, sua paixão altruísta e sua orientação àqueles que se preocupam com as pessoas, a justiça e a verdade" ${ }^{1}$.

O editorial especial para esta edição foi escrito pelo Dr. Juan Gérvas e reflete a importância de se avaliar a qualidade da atenção primária à saúde (APS) a fim de que ela possa, continuamente, se fortalecer. Em decorrência disso, todos os artigos desta edição versam sobre o Instrumento de Avaliação da Atenção Primária, em inglês Primary Care Assessment Tool (PCATool), sua validação, adaptação e aplicação para a APS². Starfield e colaboradores desenvolveram, no The Johns Hopkins Populations Care Policy Center for the Underserved Populations, o PCATool, instrumento que permite mensurar a presença e a extensão dos atributos essenciais e derivados da APS ${ }^{3}$. Os quatro atributos essenciais da APS: a) acesso de primeiro contato; b) continuidade do cuidado; c) abrangência (comprehensiveness); e d) coordenação dos cuidados são subcomponentes do acesso e, portanto, a qualidade dos serviços passa pela melhoria de estruturas e processos (efetividade) que garantam o acesso tanto no nível individual - atendendo os indivíduos e suas necessidades em saúde - como no nível populacional, em que o acesso volta-se à dimensão ética da equidade, oferecendo mais atenção para quem mais necessita ${ }^{4}$.

Durante sua vida de pesquisadora, Starfield examinou os problemas que surgem para a implantação de uma atenção primária efetiva, oferecendo uma base para o treinamento de profissionais da APS, estimulando a pesquisa e auxiliando médicos, profissionais e gestores da saúde na compreensão da importância da APS para a saúde da população, bem como suas dificuldades e desafios 5 .

Em termos de desafios, o ano de 2013 foi marcado por disputas políticas importantes no SUS e na APS brasileira. Um ano estimulante, em que a profissão médica esteve no centro dos debates e, em particular, a especialidade de Medicina de Família e Comunidade (MFC). O programa 'Mais Médicos' trouxe à tona o tema da formação médica e forçou um posicionamento das entidades de classe, do Ministério da Saúde e Educação no sentido da qualificação dos médicos brasileiros. Pode-se afirmar que a participação da diretoria da SBMFC tem sido fundamental para o debate sobre a obrigatoriedade da residência médica para se exercer a profissão no País e da necessidade de se garantir $40 \%$ das vagas de residência para MFC.

Um país que pretende construir um SUS universal, equânime e abrangente necessita construir uma APS forte, o que implica formar médicos de família e comunidade para atuarem na porta de entrada desse sistema e coordenarem as necessidades em saúde das pessoas sob sua responsabilidade.

Como citar: Norman AH, Norman JA. PCATool: instrumento de avaliação da atenção primária. Rev Bras Med Fam Comunidade. 2013; 8(29):225-6. Disponível em: http://dx.doi.org/10.5712/ rbmfc8(29)838 
A RBMFC vem cumprindo seu papel fundamental na divulgação de pesquisas na área da saúde, com enfoque principal na MFC e na APS. Em 2013, foram feitas várias modificaçóes na revista, tanto externas (novo layout da capa e identidade visual) como internamente, na criação de nova seção e na revisão e redação dos conteúdos dos textos nos três idiomas disponíveis em nosso website.

Nesta última edição de 2013, gostaríamos de agradecer à diretoria da SBMFC; aos avaliadores que voluntariamente têm colaborado com seu tempo e expertise, assegurando assim a qualidade dos conteúdos publicados pela RBMFC; aos autores que nos enviam seus trabalhos científicos e aos nossos leitores. Também, nosso agradecimento aos membros do conselho editorial; ao Dr. Michael Duncan (editor da seção Artigos de Revisão Clínica); à editora adjunta Thayse Palhano de Melo; ao bibliotecário David Milhomens; e à equipe da Editora Cubo. Desejamos a todos um excelente final de ano e que em 2014 a RBMFC/SBMFC possam contribuir ainda mais para a APS brasileira.

\section{Referências}

1. Stange KC. Barbara Starfield: Passage of the Pathfinder of Primary Care. Ann Fam Med. 2011; 9(4): 292-296. http://dx.doi.org/10.1370/afm.1293

2. Brasil. Ministério da Saúde. Departamento de Atenção Básica. Secretaria de Atenção à Saúde. Manual do Instrumento de Avaliação da Atenção Primária à Saúde: Primary Care Assessment Tool PCATool-Brasil. Brasília: Ministério da Saúde; 2010. Disponível em: http://bvsms.saude.gov.br/ bvs/publicacoes/manual_avaliacao_pcatool_brasil.pdf

3. Harzheim E, Starfield B, Rajmil L, Álvarez-Dardet C, Stein AT. Consistência interna e confiabilidade da versão em português do Instrumento de Avaliação da Atenção Primária (PCATool-Brasil) para serviços de saúde infantil. Cad Saúde Pública. 2006; 22(8): 1649-1659 PMid:16832536. http:// dx.doi.org/10.1590/S0102-311X2006000800013

4. Campbell SM, Roland MO, Buetow SA. Defining quality of care. Soc Sci Med. 2000; 51(11): 1611-1625. http://dx.doi.org/10.1016/S02779536(00)00057-5

5. Starfield B. Primary care: concept, evaluation and policy. New York: Oxford University Press; 1992. 